\title{
Do "mudsplashes" induce tactile change blindness?
}

\author{
Alberto Gallace \\ University of Oxford, Oxford, England \\ and Università degli Studi di Milano, Bicocca, Milan, Italy \\ Hong Z. TAN \\ Purdue University, West Lafayette, Indiana \\ AND \\ Charles Spence \\ University of Oxford, Oxford, England
}

\begin{abstract}
The phenomenon of change blindness (the surprising inability of people to correctly perceive changes between consecutively presented displays), primarily reported in vision, has recently been shown to occur for positional changes presented in tactile displays as well. Here, we studied people's ability to detect changes in the number of tactile stimuli in successively presented displays composed of one to three stimuli distributed over the body surface. In Experiment 1, a tactile mask consisting of the simultaneous activation of all seven possible tactile stimulators was sometimes presented between the two to-be-discriminated tactile displays. In Experiment 2 , a "mudsplash" paradigm was used, with a brief irrelevant tactile distractor presented at the moment of change of the tactile display. Change blindness was demonstrated in both experiments, thus showing that the failure to detect tactile change is not necessarily related to (1) the physical disruption between consecutive events, (2) the effect of masking covering the location of the change, or (3) the erasure or resetting of the information contained within an internal representation of the tactile display. These results are interpreted in terms of a limitation in the number of spatial locations/events that can be consciously accessed at any one time. This limitation appears to constrain change-detection performance, no matter the sensory modality in which the stimuli are presented.
\end{abstract}

The phenomenon of change blindness refers to the surprising inability of people to correctly detect visual changes from one scene to the next, both in laboratory settings and under more ecologically valid conditions (e.g., DiVita, Obermayer, Nugent, \& Linville, 2004; French, 1953; Hochberg, 1968; Rensink, O’Regan, \& Clark, 2000; Simons \& Levin, 1997; Simons \& Rensink, 2005; Velichkovsky, Dornhoefer, Kopf, Helmert, \& Joos, 2002). The phenomenon of change blindness has been interpreted as providing important clues about the mechanisms behind access to consciousness and the representation of visual events (e.g., Cohen, 2002; Gallace \& Spence, in press; Kim \& Blake, 2005; Noë, Pessoa, \& Thompson, 2000; O’Regan, 1992; O’Regan \& Noë, 2002; Rensink et al., 2000; VanRullen \& Koch, 2003a).

The inability of participants to detect changes has also been reported recently within the auditory modality (where the phenomenon has been labeled change deafness; see, e.g., Chan \& Spence, 2006; Eramudugolla, Irvine, McAnally, Martin, \& Mattingley, 2005; Vitevitch, 2003), and even within the tactile modality (Gallace, Tan, $\&$ Spence, 2006a). In particular, a recent study conducted in our laboratory (Gallace et al., 2006a) demonstrated that participants frequently fail to detect the presence of positional changes between simple consecutive tactile patterns (composed of two or three vibrotactile stimuli) presented across their body surface. That is, when the position of a stimulus that is part of a tactile pattern changes (thus giving rise to a new pattern) during the presentation of a tactile mask or after a 110-msec blank interval (i.e., in a tactile analogue of the visual flicker paradigm; see Rensink, O'Regan, \& Clark, 1997), a significant percentage (up to $30 \%$ ) of changes go unnoticed. This result is particularly surprising given the limited number of stimuli (never exceeding three) presented in the displays, and the extended time period in which participants could make their response (up to $10 \mathrm{sec}$ ).

Many studies have demonstrated that the human visual system is particularly sensitive to the addition of new objects to visual scenes (e.g., Gellatly \& Cole, 2000; Jonides, 1981). This might be related to the capacity of the new object to capture visual attention or to the ability of its neural representation to access consciousness (see Lamme, 2003) and/or to elicit an orientation response toward its spatial position. Indeed, Cole, Kentridge, Gellatly, and Heywood (2003) recently reported that the addition of

A. Gallace, alberto.gallace@psy.ox.ac.uk 
events was detected more frequently (than the removal of objects) during change (though see Mondy \& Coltheart, 2000). However, despite this evidence, it has also been reported that participants sometimes miss changes consisting of the appearance of an object in a visual scene if other irrelevant visual transients occur at the same time as the change (O'Regan, Rensink, \& Clark, 1999). This result would appear to suggest that the addition of objects to a visual scene may not have a special status in terms of eliciting successful change detection (or in terms of attracting attention to the position of the change; Watson \& Humphreys, 1995) after all. Therefore, the question of the "special status" of new visual events appears to still be a matter of some debate.

It has recently been shown that tactile cues presented on the body surface can be more effective than visual cues in alerting people to the presence of potentially dangerous events in extrapersonal space (e.g., Ho, Reed, \& Spence, 2006; Ho, Tan, \& Spence, 2005). It has also been argued that tactile stimuli may have an automatic ability to capture a person's attention (see Geldard, 1960; Von Haller Gilmer, 1960, 1961). Taken together, such observations suggest that the addition of tactile events to a pattern might be less susceptible to the phenomenon of change blindness than is the addition of visual events. That is, the presentation of tactile stimuli across the body might be more effective (and/or prioritized) in terms of accessing consciousness and/or eliciting a correct detection response (see Spence \& McGlone, 2001).

The questions of whether or not changes involving the addition or deletion of a tactile event from tactile displays may elicit change blindness and of whether or not sudden onset events (i.e., new events being added to a display; $\mathrm{cf}$. Cole et al., 2003) have a special status in terms of tactile processing have not been addressed empirically before. In Experiment 1, using a flicker paradigm, we studied the ability of participants to detect the presence of changes composed of the appearance or disappearance of a stimulus between consecutively presented tactile patterns. In Experiment 2 , using a one-shot procedure, we studied in more detail the difference between a new stimulus being added to a tactile display and an old stimulus being deleted from the display. If the presentation of a new tactile stimulus has a special status with regard to tactile information processing (i.e., in terms of the alerting capability of the stimulus and/or its access to consciousness), we would not expect to observe change blindness under conditions in which a new stimulus is added to a display. If, as has been reported in certain previous experiments on visual change blindness, the appearance of a stimulus does not have a special role, in terms either of its alerting capability and/or its ability to access consciousness (see Folk, Remington, \& Johnston, 1992; J. Miller, 1989; Watson \& Humphreys, 1995), we should expect to observe a failure to perceive changes in the number of stimuli composing successively presented tactile displays (i.e., as reported previously for the ease of positional changes; e.g., Gallace et al., 2006a).

Note that the large majority of cognitive and neurophysiological theories regarding consciousness and the representation of events/scenes have been based on the evidence provided by visual studies (e.g., Crick \& Koch, 1998; Dennet, 1991; Logothetis, 1998; Noë \& O'Regan, 2000; VanRullen \& Koch, 2003b; see also Kim \& Blake, 2005). Any failure to detect the appearance and disappearance of stimuli presented in tactile displays would therefore provide important clues with regard to the limitations of the conscious representation of events in other sensory modalities.

\section{EXPERIMENT 1}

\section{Method}

Participants. Eleven right-handed participants (5 males and 6 females) took part in this experiment (mean age 26.2 years, ranging from 19 to 32 years) in exchange for course credits. All of the participants reported normal tactile perception.

Apparatus and Materials. The experiment was conducted in a normally illuminated room, with each participant sitting on a comfortable chair. The vibrotactile stimuli were presented by means of seven resonant-type tactors (Part No. VBW32; Audiological Engineering Corp., Somerville, MA), with $1.6 \times 2.4 \mathrm{~cm}$ vibrating surfaces. The tactors were placed on the participant's body on top of any clothing they were wearing by means of Velcro strips (see Figure 1). The participants were unable to see any of the tactors directly under the Velcro strips. The seven body sites where stimulation could be delivered were selected on the basis of their relative "salience" (i.e.,

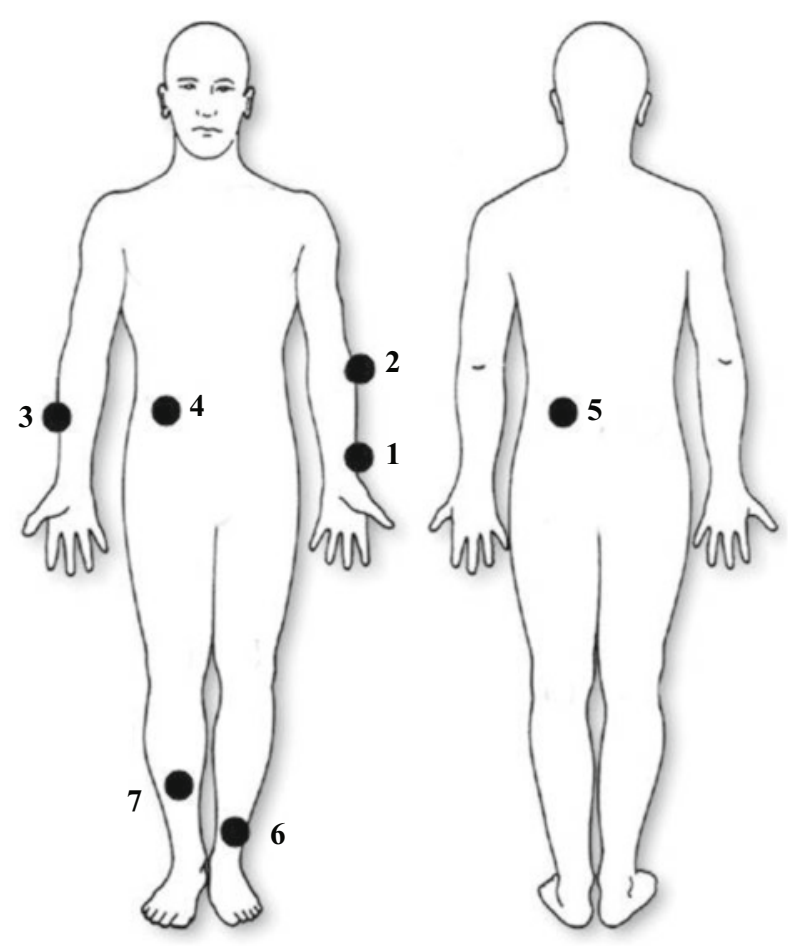

Figure 1. Positions on the body surface where the tactors were placed: (1) left wrist, (2) just below the left elbow, (3) midway between the wrist and elbow on the right arm, (4) on the waistline, to the right of the body midline, (5) on the back, to the left of the body midline, (6) just above the left ankle, and (7) midway between the ankle and knee on the right leg (cf. Gallace, Tan, \& Spence, 2006b; Geldard \& Sherrick, 1965). 
defined as the capability of a given stimulus position across the body to be correctly identified and reported when stimulated; see Geldard $\&$ Sherrick, 1965), in order to minimize localization or confusion errors (cf. Gallace, Tan, \& Spence, 2006b; Geldard \& Sherrick, 1965). The vibrators were driven by means of a custom-built nine-channel amplifier circuit that drove each tactor independently at $290 \mathrm{~Hz}$. The intensity of each tactor was adjusted individually at the beginning of the experiment, so that each vibrotactile stimulus could be perceived clearly, and all of the stimuli were perceived to be of similar intensity. White noise was presented over closed-ear headphones at $70 \mathrm{~dB}(\mathrm{~A})$ to mask any sounds made by the operation of the vibrotactile stimulators.

The experiment was composed of three blocks of trials. In each block, the stimuli consisted of two, alternating 200-msec vibratory patterns, presented repeatedly. In one block of trials, the stimuli were presented sequentially, without any gap between them. In a second block of trials, the two patterns were separated by a masked interval consisting of a 50-msec empty interval, followed by a $10-\mathrm{msec}$ vibrotactile mask (consisting of the simultaneous activation of all seven tactors), and then by a second 50-msec empty interval (totaling $110 \mathrm{msec}$ ). ${ }^{1}$ The first pattern always consisted of two or three tactors that were activated equally often at different body locations (see Figure 2). In both the change and no-change conditions, the second vibratory pattern was composed of either two or three activated tactors. In $50 \%$ of the change trials, a new stimulus was added to the display (addition trials), whereas in the other $50 \%$ of the change trials, one stimulus was removed from the display (deletion trials; see Figure 2). In the no-change condition, the same vibratory pattern was presented repeatedly throughout the trial. The sequence of stimulation was repeated for the duration of the trial $(10 \mathrm{sec})$, or until the participant responded. Each block of trials was divided into two equal parts, separated by a short break. The order of presentation of the two block types was randomized across participants. Note that the number of tactors activated in any pattern never exceeded three, given recent evidence that people's ability to detect simultaneously presented stimuli over the body surface shows a marked decrease if the number of tactors activated exceeds this number (Gallace et al., 2006b; see also Posey \& James, 1976).

Procedure. The participants were instructed to press one of two keys on a computer keyboard as soon as they decided whether or not a change was present in a given display. The trial was terminated if no response was made within $10 \mathrm{sec}$ of the initial onset of the stimuli. No feedback was given regarding the correctness of a participant's response. For each experimental condition, 80 trials were presented. In $50 \%$ of the trials, a change between the two patterns was presented (equiprobably an addition or deletion change), and in the remaining trials, no change occurred. Each participant completed a total of 160 trials. At the beginning of each experimental block, 20 practice trials were presented, in which visual feedback (the word "correct" or "incorrect") was provided on the screen. The participants repeated the practice trials if their performance failed to exceed $65 \%$ correct.

\section{Results and Discussion}

Trials in which participants failed to make a response $(<3 \%$ of trials overall) were not included in the data analyses. The percentage of correct change-detection responses was used to calculate $d^{\prime}$ and $\beta$ for each block type, using signal detection theory (see, e.g., Macmillan \& Creelman, 2004). These measures were then submitted to two paired-samples $t$ tests. Analysis of the $d^{\prime}$ data revealed a significant difference between the masked interval and no-interval conditions $[t(10)=9.8, p<.0001]$, with worse performance (i.e., lower $d^{\prime}$ values) being reported when the two displays were separated by the tactile mask than when they were not. The analysis of $\beta$ failed to reveal any significant effect of block type $[t(10)=1.43$, n.s.]; see Figures $3 \mathrm{~A}$ and $3 \mathrm{~B}$.

The percentages of errors were then calculated separately for the addition and deletion trials. These data were submitted to an ANOVA with the factors of block type and type of change (addition vs. deletion). Analysis of the error data revealed significant main effects of block type $[F(1,10)=30.6, p<.001]$ and of type of change $[F(1,10)=10.5, p<.01]$, but no interaction between these two factors $[F(1,10)=1.48, p=.25]$. The percentage of errors was higher in the deletion condition $(M=$ $37.9 \%)$ than in the addition condition $(M=26.6 \%)$, and higher in the masked interval $(M=34.3 \%)$ than in the no-interval blocks $(M=16.3 \%)$.

The percentage of errors in the masked condition was then split between misses (when a change was present but a "no-change" response was made) and false alarms (when no change was present but a "change" response was given) as a function of the responses given by the participants. A paired $t$ test performed on these data failed to reveal a significant difference between misses and false alarms $[t(10)=1.33, p=.21]$. Note, however, that in absolute terms, participants were more likely to make a no-change response when a change was present in the display than to press the change button when no changes were actually present in the display (see Figure 3C), as has frequently been reported previously in the visual change blindness literature (see, e.g., Rensink, 2002).

The results of Experiment 1 therefore demonstrate that under certain conditions, people can fail to detect the presence of a change between two sequentially presented vibrotactile patterns delivered over the body surface (cf. Gallace et al., 2006a). The worst change-detection performance (i.e., the lowest $d^{\prime}$ ) was reported when a vibrotactile mask was presented between the two to-be-discriminated vibrotactile patterns, and the best performance was observed when the two patterns alternated without any gap. Under the latter conditions, error rates were very low and $d^{\prime}$ values were high. By contrast, in the masked interval condition, participants failed to detect the presence of a change on more than $30 \%$ of the trials. This pattern of results is similar to that reported in previous studies of visual change detection (e.g., French, 1953; Hochberg, 1968; Rensink, 2002; Simons \& Levin, 1997; Simons \& Rensink, 2005), as well as in our previous study of tactile change detection involving changes in the position of a tactile stimulus (Gallace et al., 2006a).

The results of Experiment 1 also highlighted the presence of a significant difference in performance accuracy between the trials starting with the addition of an event in comparison with trials starting with the deletion of an event from the display. In particular, participants' changedetection performance was better when the trial started with a new object being added to the tactile display than when the trial started with an old object being removed from the display. This result is consistent with the results reported by Cole et al. (2003), who used visual displays, and might be suggestive of new events having a special status (regardless of whether they are visual or tactile), in 
A No Interval

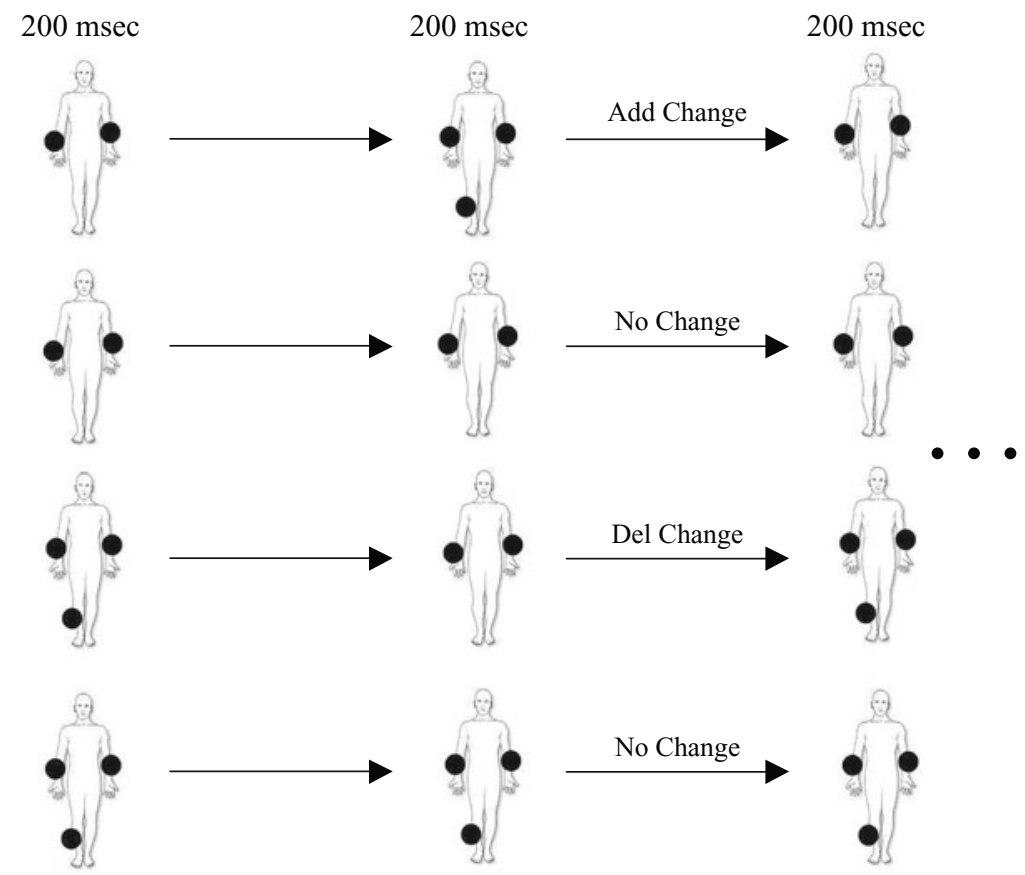

Pattern 1

Pattern 2

Pattern 1

\section{B Masked Interval}

$200 \mathrm{msec} \quad 50 \mathrm{msec} 10 \mathrm{msec} 50 \mathrm{msec} \quad 200 \mathrm{msec} \quad 50 \mathrm{msec} 10 \mathrm{msec} \quad 50 \mathrm{msec} \quad 200 \mathrm{msec}$
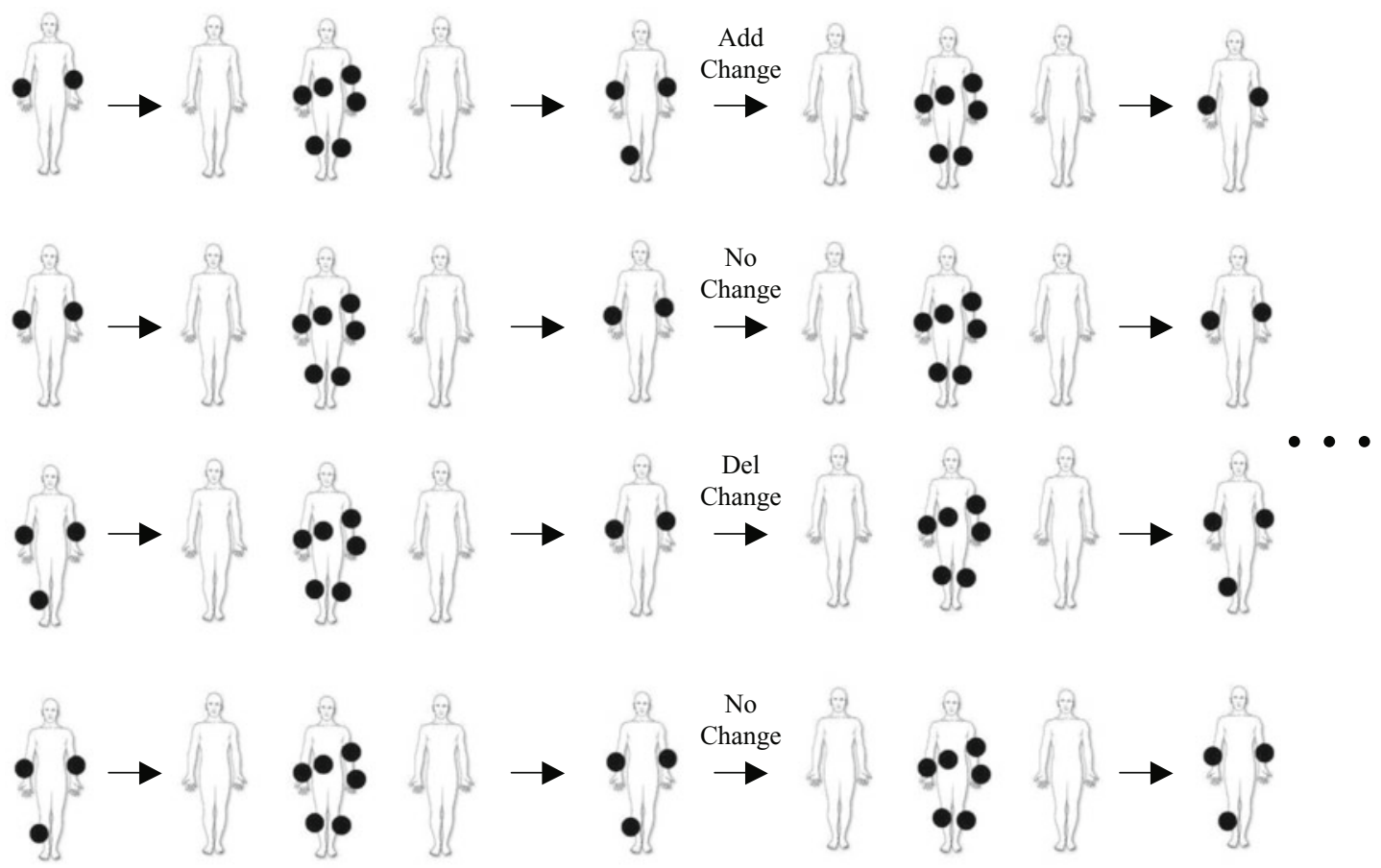

Pattern 1

Masked Interval

\section{Pattern 2}

Masked Interval

Pattern 1

Figure 2. Schematic illustration of the sequence of events presented in each trial of Experiment 1: (A) no-interval trial, (B) masked interval trial. Change trials starting with the addition of a stimulus to the display (add) and change trials starting with the deletion of a stimulus from the display (del) are represented. Note that no-change trials were composed of either two or three tactors activated in the display. The times shown above each figure indicate the duration (in milliseconds) of each event. 

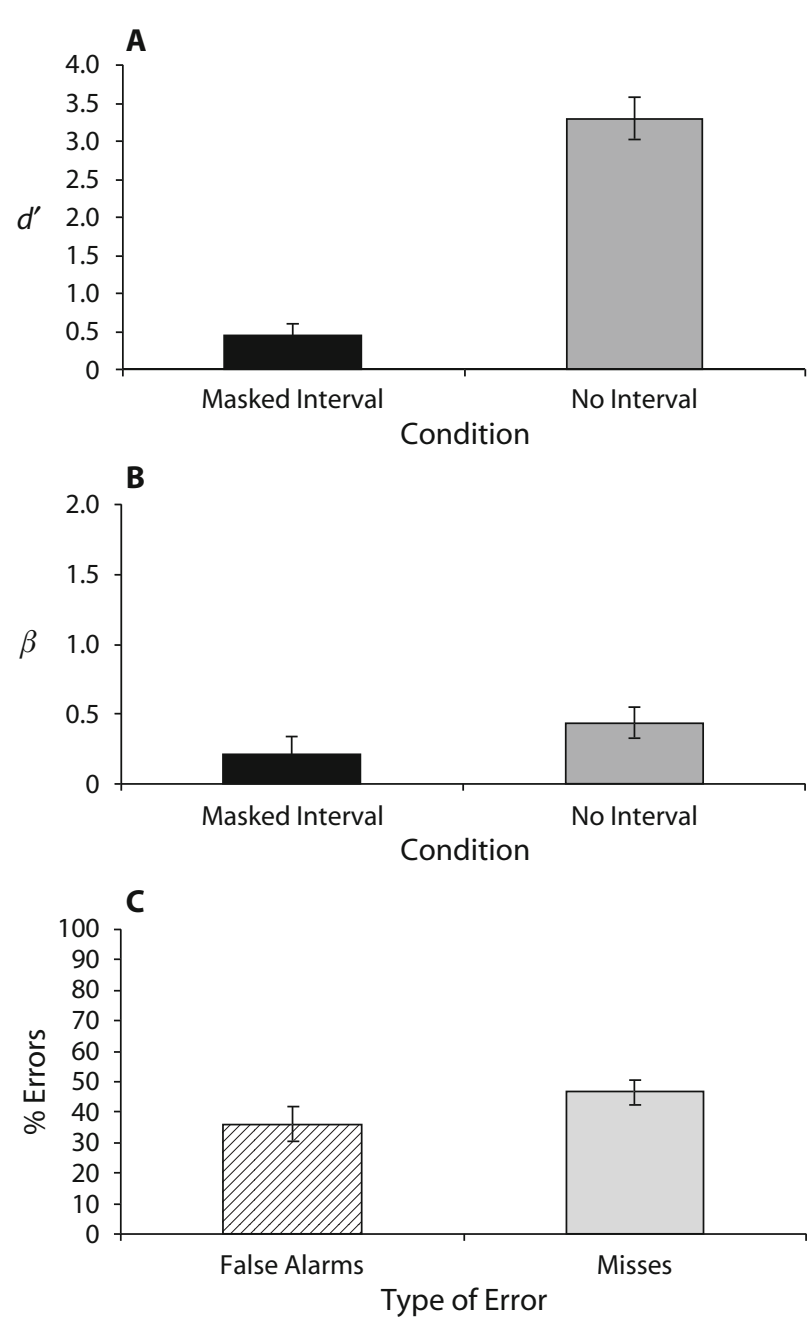

Figure 3. Performance in each experimental block of Experiment 1: (A) mean $d^{\prime}$ values, (B) mean $\beta$ values, (C) mean error rates divided in false alarm and miss responses obtained in the masked condition. Error bars represent the standard errors of the means.

terms of having a higher priority access to consciousness, or in terms of the higher amount of information that they carry being preserved between consecutive presentations (e.g., Cole et al., 2003; Gellatly \& Cole, 2000; Jonides, 1981). However, it should be noted that the phenomenon of change blindness, although somewhat less pronounced in absolute terms, was still present for trials starting with the addition of an event to the tactile display, with error rates of up to $45 \%$ being reported. This might therefore suggest that the onset of new tactile events is not sufficient, in and of itself, to guarantee successful tactile change detection; it only improves performance somewhat.

In Experiment 2, we studied whether the phenomenon of tactile change blindness reported in Experiment 1 might be exclusively related to (1) the disruption of the temporal continuity between consecutive tactile events, (2) the effect of masking occurring at the location of the change, or (3) the erasure, or resetting, of the information contained within an internal representation of the tactile display (tactile working memory) caused by the presentation of a mask (see O’Regan et al., 1999; Simons \& Levin, 1997). In order to address these questions, we developed a tactile analogue of the "mudsplash" paradigm used previously in studies of visual change blindness (e.g., O'Regan et al., 1999). In this paradigm, the tactile patterns that participants had to compare were presented without any temporal gap between them, and irrelevant tactile transients were superimposed on the display at the time at which the change occurred. It should be noted that no physical disruption, nor masking of the position of the change, occurred in this mudsplash paradigm. Therefore, if changes were still to go undetected under such conditions, none of the interpretations proposed thus far would appear sufficient to account for the phenomenon of tactile change blindness. Instead, the results would suggest that tactile change blindness is determined by the failure of the representation of the changed stimulus to access consciousness or to draw attention to its location, given the simultaneous presence of a competing transient in the display.

In Experiment 2, we used a "one-shot" procedure (cf. Cole et al., 2003, for a visual study using a similar paradigm) in order to have better control of the addition and deletion conditions of stimulus presentation. The two tactile displays were no longer alternated continuously (as in the flicker paradigm), but instead were presented only once, one after the other.

\section{EXPERIMENT 2}

\section{Method}

Participants. Fifteen right-handed participants $(7$ males and 8 females) took part in this experiment (mean age 26.4 years, range of 19-32 years) in exchange for a $£ 5$ (U.K.) gift voucher. All of the participants reported normal tactile perception.

Apparatus, Materials, Design, and Procedure. The two patterns composing the tactile displays were exactly the same as those used in Experiment 1. Both the first and second patterns were presented for $2 \mathrm{sec}$. Two blocks of trials were used. In both blocks, the stimuli were presented in immediate succession on the body surface, without any temporal gap between them. The only difference between the two block types was that in the second block, a "mudsplash" consisting of a 100-msec vibrotactile stimulus was presented at the same time as the change (i.e., coincident with the onset of the second pattern). The mudsplash was presented from a position chosen randomly among the body locations that were not stimulated by any of the three vibrotactile stimulators used to make up either of the two patterns in the display. The order of presentation of the two block types was randomized across participants.

The participants were instructed to press one of two keys on a computer keyboard in order to indicate whether or not the second pattern was perceived as being different from the first. The trial was terminated if no response was made within $4 \mathrm{sec}$ of the offset of the second pattern. No feedback was given regarding the correctness of the participant's response. For each experimental condition, 80 trials were presented. A change between the two patterns was presented (equiprobably an addition or deletion change) in $50 \%$ of the trials, and in the remaining trials, no change occurred. (Note that under this condition, displays composed of two and three stimuli were presented equally often.) Each participant completed a total of 160 trials.

\section{Results and Discussion}

Trials in which participants failed to make a response $(<1 \%$ of trials overall) were not included in the data analy- 
ses. The percentage of correct change-detection responses was used to calculate $d^{\prime}$ and $\beta$ for each block type. These measures were submitted to two paired-samples $t$ tests. The analysis of the $d^{\prime}$ data revealed a significant difference between the mudsplash and no-mask conditions $[t(14)=$ $-6.63, p<.0001]$, highlighting the worse performance (i.e., lower $d^{\prime}$ ) when the two displays were separated by a tactile mudsplash than when they were not. The analysis of $\beta$ failed to reveal any significant effect of block type $[t(14)=1.23$, n.s. $]$; see Figures $4 \mathrm{~A}$ and 4B.

The percentages of errors were then calculated for the addition and deletion trials, for each of the two block types. These measures were submitted to an ANOVA with the factors of block type and type of change (addition vs. deletion). This analysis revealed significant main effects of block type $[F(1,14)=19.9, p<.0001]$ and of type of change $[F(1,14)=106.0, p<.0001]$. The interaction between block type and type of change was not significant $[F(1,14)=0.52, p=.48]$. The percentage of errors was higher in the deletion condition than in the addition condition in both the mudsplash and the no-mask block of trials (see Figure 4C).

The percentage of errors for the mudsplash condition was then split between misses (i.e., trials in which a change was present but a "no-change" response was given) and false alarms (i.e., trials in which no change was present but a "change" response was given) as a function of the participants' responses. A paired-samples $t$ test performed on these data revealed a significant difference between misses and false alarm errors $[t(14)=6.92, p<$ $.0001]$. That is, participants were more likely to press the no-change button when a change was present in the display than to press the change button when no actual changes were present in the display (see Figure 4D). This pattern of results is similar to that reported in previous experiments of visual change blindness, and demonstrates that participants fail to report the presence of changes between two consecutively presented vibrotactile displays (e.g., Cole et al., 2003).

The results of Experiment 2, showing lower $d^{\prime}$ values for the mudsplash trials, provides the first empirical evidence for the presence of change blindness following the presentation of an irrelevant tactile event superimposed onto a tactile display (i.e., a mudsplash). Moreover, the better performance observed for addition trials in comparison with deletion trials appears to confirm the visual change blindness findings reported by Cole et al. (2003), as well as replicating the results of Experiment $1 .{ }^{2}$

\section{GENERAL DISCUSSION}

The results of the two experiments reported in the present study highlight the presence of change blindness for tactile events consisting of the addition or deletion of stimuli to a display, when the to-be-compared displays are separated by a tactile mask. In Experiment 1, tactile change blindness was demonstrated using a flicker paradigm. In Experiment 2, the failure to detect tactile change was demonstrated using a mudsplash paradigm (cf. O'Regan et al., 1999; see also Rensink, 2002), in
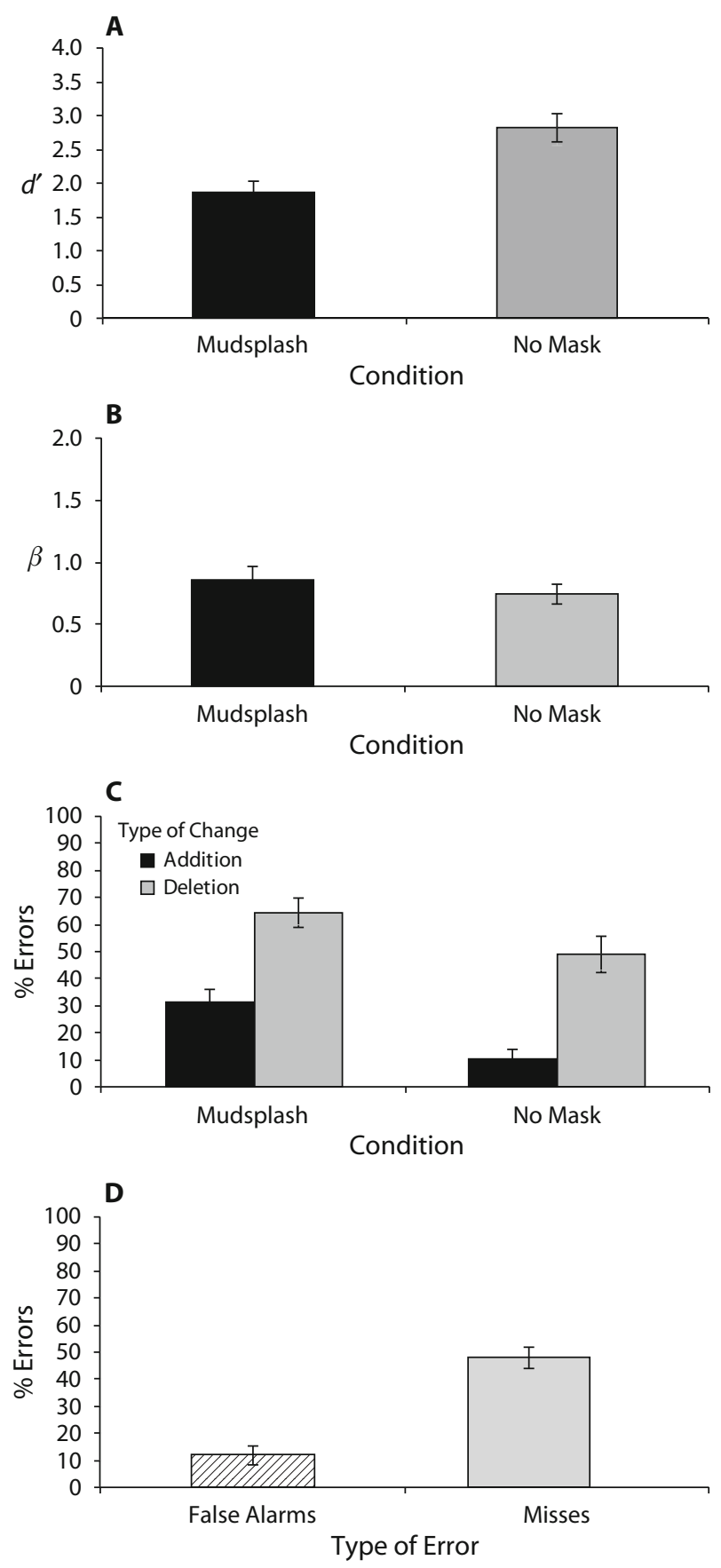

Figure 4. Performance in each experimental block of Experiment 2: (A) mean $d^{\prime}$ values, (B) mean $\beta$ values, (C) mean error rates in the deletion and addition trials (error bars represent the standard errors of the means), (D) mean error rates divided in false alarm and miss responses obtained in the mudsplash condition.

which an irrelevant tactile distractor was superimposed briefly (for $100 \mathrm{msec}$ ) onto the tactile pattern (which was presented continuously on the skin for $2 \mathrm{sec}$ ) at a position different from those used to present the tactile displays. These results demonstrate that tactile change blindness is not related exclusively to the physical disruption between consecutive events, nor to the effect of masking covering 
the location of the change, nor to the erasure or resetting of information contained in an internal representation of the tactile display attributable to the presentation of the mask. Moreover, the fact that the poor change-detection performance was observed for $d^{\prime}$ but not for $\beta$ clearly demonstrates that the phenomenon is strictly related to the perceptual processing of tactile information rather than to a bias affecting participants' responses.

The results of the two experiments reported here therefore confirm and extend the range of similarities between the change blindness effect reported in tactile and visual perception (see Gallace et al., 2006a). However, the present study also highlights some important differences in the phenomenon when tactile as opposed to visual displays are used. Indeed, failures in tactile change detection were found in the present study, which used very simple displays composed of only one to three stimuli (cf. Gallace et al., 2006a, for similar results using changes in the position of one of the vibrotactile stimuli making up one of the tactile patterns as the target event), whereas visual change blindness has primarily been reported in studies using complex scenes and/or displays composed of more than five stimuli (see Rensink et al., 2000, for studies in which participants were asked to track multiple objects in parallel).

It should be noted that visual change blindness has also been reported when only one object is presented in a stimulus display (e.g., Williams \& Simons, 2000). Specifically, Williams and Simons found that participants in their experiment were unable to detect the presence of a change to an object that was temporarily moving behind an occluder. Note, however, that in Williams and Simons's study, 3-D complex objects (called "Fribbles"; see Williams, 1997), composed of many different parts, were used. This would therefore suggest that, when transients are eliminated, not only the competition between stimuli presented from different spatial positions can result in a lack of awareness of the change, but even the competition between parts of (and/or locations across) a single object can result in change blindness.

Finally, the results of Experiment 2 show that only one distractor used as a mudsplash and presented elsewhere on the body can be sufficient to elicit tactile change blindness. (Note that for the case of visual perception, many distractors typically have to be presented in order to elicit the phenomenon; see, e.g., O'Regan \& Noë, 2002.)

Taken together, these findings could be seen to represent a robust limitation on tactile in comparison with visual information processing. This limitation might be related to the lower number of stimuli/positions that can be consciously accessed at any one time when presented within the tactile modality as opposed to the visual modality (e.g., Gallace et al., 2006b). However, the presence of large differences between the experimental setups used in studies of visual and tactile change blindness, and the very fundamental differences between the two sensory modalities themselves, make any direct comparison of the relative efficiency of change detection of one sensory modality, versus the other, difficult.
Moreover, whereas in visual change blindness experiments it is possible to limit the amount of visual information that participants have access to (by presenting visual stimuli on a monitor while conducting the experiment in an otherwise dark testing room), there might be additional tactile information available in experiments that cannot easily be controlled for by the experimenter (such as the feeling of the participant's clothes on his or her skin, though see Graziano, Alisharan, Hu, \& Gross, 2002; Holmes \& Spence, 2006; points of contact of the participant's body on the chair; and pressure on the response keys). Therefore, the number of uncontrolled stimuli present in the tactile scene might help to explain any difference reported between tactile and visual processing, without necessarily having to argue for intermodal differences in the accuracy of change-detection performance between vision and touch.

It might be possible that the failure to detect changes consisting of new stimuli being added to a display relates to the fact that the transients used by the brain to detect the occurrence of a change are eliminated by the presence of a mask. In particular, the vibrotactile mask can be seen as an additional transient, reducing the uniqueness of the change (in terms of being the only transient in the scene), and therefore perhaps reducing the change's ability to capture attention/elicit awareness regarding its location. However, this interpretation does not really agree with the results of previous studies of visual perception, and in particular with the observation that a new object being the only transient in the display is not a necessary condition for attentional capture to occur (see Cole et al., 2003, for further discussion of this point). Specifically, results from onset "singleton" tasks show that attention can also be captured by a changing item when its onset coincides with the onset of other irrelevant items in the display (e.g., Jonides \& Yantis, 1988; Yantis \& Hillstrom, 1994; Yantis \& Jonides, 1984).

Note, however, that it has been reported that the presence of additional transient noise in a display at the time of an onset change leads to less attentional capture (e.g., Martin-Emerson \& Kramer, 1997). Finally, it has been proposed that attention is not captured by a new object appearing in a display, but only by the transients that the new object creates (e.g., Franconeri, Hollingworth, \& Simons, 2005). That is, changes in some qualities of the stimuli (such as motion and brightness) strongly activate transient channels in the visual system (which are maximally sensitive to these characteristics of visual information; see Breitmeyer \& Ganz, 1976), resulting in an orientation response (e.g., Jonides \& Yantis, 1988). Although the present studies do not directly address the capture of attention, but rather change detection, the results should nevertheless be considered in order to derive a more comprehensive theory regarding the mechanism underlying the detection of new objects. (Note, indeed, that onset singleton experiments can be thought of as analogous to one-shot change blindness experiments; Cole et al., 2003.) Specifically, further exploration of new-object-detection performance in tactile singleton tasks is needed in order to 
evaluate the link between attentional capture/orientation responses and the tactile change blindness phenomenon reported here.

It has been suggested that the representation of a visual scene may be limited to the number of items that can be held in visual short-term memory (STM) at any one time (e.g., G. A. Miller, 1956; Pashler, 1988; Pylyshyn \& Storm, 1988; Rensink, 2002). Following on from this, another possible account of the results reported here might be related to the role played by tactile STM in retaining a veridical representation of the two vibrotactile patterns that have to be compared in order to successfully detect that a tactile change has occurred. Although there are still very few published studies about tactile STM, the available evidence suggests that the immediate memory span for tactile stimuli following brief (i.e., 100-msec) presentation varies from 3.5 to 7.5 stimuli, and that tactile STM performance declines to an asymptotic level (i.e., the lowest level of performance in the recollection task) within $45 \mathrm{sec}$ of stimulus presentation (e.g., Bliss, Crane, Mansfield, \& Townsend, 1966; Gilson \& Baddeley, 1969; G. A. Miller, 1956; cf. Hillstrom, Shapiro, \& Spence, 2002). Given that vibrotactile target stimuli were never presented to more than three body locations at any one time in the present study, and given the fact that the interval between the two patterns was very brief $(110 \mathrm{msec}$, as in our previous study of tactile change blindness; cf. Gallace et al., 2006a), a failure of tactile STM would not appear to provide a satisfactory account of our results. However, further studies should be conducted in order to explore the duration of tactile STM for stimuli presented across the body surface. Indeed, one might expect there to be differences between STM for stimuli presented on the body versus stimuli presented on the fingers (where stimuli have been presented in all previous studies of tactile STM; e.g., Bliss et al., 1966; Gilson \& Baddeley, 1969).

Although a failure of STM in being able to retain the information regarding the stimuli presented over the body surface appears to be unlikely in the present study, the possibility that, when a masking stimulus was presented, a sort of tactile "suffix effect" could have disrupted the memory for the first pattern presented, should at least be considered (see Watkins \& Watkins, 1974). Indeed, it has been demonstrated previously that when participants had to recall the order of a series of eight tactile stimuli presented to the fingertips, performance was partially disrupted by the presentation of a "suffix" consisting of a light stroke across the fingers, just at the end of the sequence to be recalled (Watkins \& Watkins, 1974; see Crowder \& Morton, 1969 , for a similar effect obtained using auditory stimuli). Note, however, that whereas Watkins and Watkins's suffix was presented at all the locations that had been stimulated previously, probably erasing the content of the sensory memory of the last stimuli in the sequence presented, the mask used in our Experiment 2 was always presented from a nonstimulated location, making it difficult to interpret our results solely in terms of a tactile suffix effect. It would be interesting in future research to investigate the tactile suffix effect for sequences of stimuli presented at different spatial locations across the body surface, rather than being limited to the fingertips.

Finally, it has been suggested that change blindness may reflect limited-capacity mechanisms affecting information processing under conditions of multiple simultaneous stimulation (e.g., Wright, Green, \& Baker, 2000). This might be related to the parallel deployment of attentional resources over multiple elements in the scene (e.g., Wright et al., 2000), or to the limitation in the number of stimuli/ spatial positions that can access consciousness at any one time (e.g., Atkinson, Campbell, \& Francis, 1976; Jevons, 1871; Pylyshyn \& Storm, 1988; Rensink et al., 2000; VanRullen \& Koch, 2003a; see also Gallace et al., 2006b, for the limitations affecting tactile numerosity judgments). Interestingly, the number of stimuli necessary in order to elicit change blindness seems to be related to the number of tactile or visual stimuli/positions that can be reported at any one time (e.g., Gallace et al., 2006b; Gallace, Tan, \& Spence, 2007; VanRullen \& Koch, 2003a). Indeed, people have been shown to make errors in correctly reporting the number of tactile stimuli presented at any one time for displays composed of no more than two or three stimuli. As shown here, they also fail to detect changes to displays composed of two or three stimuli. In vision, people fail to detect changes when a minimum of five stimuli are presented in the display/scene (see Rensink et al., 2000; though see Williams \& Simons, 2000). The same number of stimuli has been shown to constitute the boundary between correct and defective numerosity judgment performance in vision (e.g., Atkinson et al., 1976). Therefore, it is conceivable that change blindness in both vision and touch might be related to the failure of the spatial position of the change to reach awareness and/or draw spatial attention to itself within a multisensory/amodal spatial representation (where the change took place). This might be determined by the competition between concurrently stimulated positions (see Cole et al., 2003; VanRullen \& Koch, 2003a; see also Calvin, 1998, for a theory of awareness of events in terms of a Darwinian competition in the cerebral cortex), and/or by the limited processing resources that are available (see Wright et al., 2000).

Interestingly, Downar, Crawley, Mikulis, and Davis (2000) used event-related fMRI to highlight a righthemisphere network including the temporoparietal junction (the area typically correlated with the awareness of spatial information; Karnath, Ferber, \& Himmelbach, 2001; Vallar, 2001) involved in the detection of visual, auditory, and tactile change. Furthermore, it has also been reported that presenting a noninformative vibrotactile stimulus on a participant's torso can significantly improve visual change-detection performance, at least when the vibrotactile events are spatially predictive with regard to the likely location of the vibrotactile change (Tan, Gray, Young, \& Traylor, 2003; see also Lindeman, Yanagida, Sibert, \& Lavine, 2003). Such results are consistent with the view that change blindness may reflect a more general multimodal/amodal mechanism (possibly related to the awareness of spatial information), rather than a specific unimodal, underlying mechanism. 
Now that the presence of specific constraints on the phenomenon of unimodal tactile change blindness has been demonstrated, future research should address the question of whether change blindness within different sensory modalities might have a common underlying cause (cf. Auvray, Gallace, Tan, \& Spence, 2006, in press). It will also be of particular interest in future research to study whether tactile change blindness can be elicited using a visual mask, or under conditions in which visual transients (or mudsplashes) are concurrently presented. Finally, the possibility that the representation of tactile stimuli that do not have access to consciousness for purposes of explicit reporting may still be accessed using alternative procedures (i.e., more indirect or implicit) should also be investigated (e.g., Fernandez-Duque \& Thornton, 2000; Hollingworth, Williams, \& Henderson, 2001; see also Cohen, 2002, and cf. Gallace \& Spence, in press).

\section{AUTHOR NOTE}

A.G. was supported by a grant from the Università degli Studi di Milano, Bicocca, Italy. H.Z.T. and C.S. were supported by a Network Grant from the Oxford McDonnell-Pew Centre for Cognitive Neuroscience. Correspondence concerning this article should be addressed to A. Gallace, Department of Experimental Psychology, University of Oxford, South Parks Road, Oxford OX1 3UD, England (e-mail: alberto.gallace@psy .ox.ac.uk).

\section{REFERENCES}

Atkinson, J., Campbell, F. W., \& Francis, M. R. (1976). The magic number $4 \pm 0$ : A new look at visual numerosity judgements. Perception, 5, 327-334.

Auvray, M., Gallace, A., Tan, H. Z., \& Spence, C. (2006). Change blindness between vision and touch: Evidence for the amodal encoding of spatial position. Manuscript submitted for publication.

Auvray, M., Gallace, A., Tan, H. Z., \& Spence, C. (in press) Crossmodal change blindness between vision and touch. Acta Psychologica.

Bliss, J. C., Crane, H. D., Mansfield, P. K., \& Townsend, J. T. (1966). Information available in brief tactile presentations. Perception \& Psychophysics, 1, 273-283.

Breitmeyer, B., \& GANZ, L. (1976). Implications of sustained and transient channels for theories of visual pattern masking, saccadic suppression, and information processing. Psychological Review, 83, $1-36$.

Calvin, W. H. (1998). Competing for consciousness: A Darwinian mechanism at an appropriate level of explanation. Journal of Consciousness Studies, 5, 389-404.

Chan, J. S., \& Spence, C. (2006). Change deafness: An auditory analogue of visual change blindness? Manuscript submitted for publication.

CoHen, J. (2002). The grand grand illusion illusion. Journal of Consciousness Studies, 9, 141-157.

Cole, G. G., Kentridge, R. W., Gellatly, A. R. H., \& Heywood, C. A. (2003). Detectability of onsets versus offsets in the change detection paradigm. Journal of Vision, 3, 22-31.

CRICK, F., \& КосH, C. (1998). Consciousness and neuroscience. Cerebral Cortex, 8, 97-108.

Crowder, R. G., \& Morton, J. (1969). Precategorical acoustic storage (PAS). Perception \& Psychophysics, 5, 365-373.

DenNet, D. C. (1991). Consciousness explained. Boston: Little, Brown.

DiVita, J., Obermayer, R., Nugent, W., \& Linville, J. M. (2004). Verification of the change blindness phenomenon while managing critical events on a combat information display. Human Factors, 46, 205-218.

Downar, J., Crawley, A. P., Mikulis, D. J., \& Davis, K. D. (2000). A multimodal cortical network for the detection of changes in the sensory environment. Nature Neuroscience, 3, 277-283.

Eramudugolla, R., Irvine, D. R. F., McAnally, K. I., Martin, R. L., \& Mattingley, J. B. (2005). Directed attention eliminates "change deafness" in complex auditory scenes. Current Biology, 15, 1108-1113.

Fernandez-Duque, D., \& Thornton, I. M. (2000). Change detection without awareness: Do explicit reports underestimate the representation of change in the visual system? Visual Cognition, 7, 323-344.

FolK, C. L., Remington, R. W., \& Johnston, J. C. (1992). Involuntary covert orienting is contingent on attentional control settings. Journal of Experimental Psychology: Human Perception \& Performance, 18, 1030-1044.

Franconeri, S. L., Hollingworth, A., \& Simons, D. J. (2005). Do new objects capture attention? Psychological Science, 16, 275-281.

FRENCH, R. S. (1953). The discrimination of dot patterns as a function of number and average separation of dots. Journal of Experimental Psychology, 46, 1-9.

Gallace, A., \& Spence, C. (in press). The cognitive and neural correlates of "tactile consciousness": A multisensory perspective. Consciousness \& Cognition.

Gallace, A., Tan, H. Z., \& Spence, C. (2006a). The failure to detect tactile change: A tactile analogue of change blindness. Psychonomic Bulletin \& Review, 13, 300-303.

Gallace, A., Tan, H. Z., \& Spence, C. (2006b). Numerosity judgments for tactile stimuli distributed over the body surface. Perception, 35, 247-266.

Gallace, A., Tan, H. Z., \& Spence, C. (2007). Multisensory numerosity judgments for visual and tactile stimuli. Perception \& Psychophysics, 69, 487-501.

GelDARD, F. A. (1960). Some neglected possibilities of communication. Science, 131, 1583-1588.

Geldard, F. A., \& Sherrick, C. E., JR. (1965). Multiple cutaneous stimulation: The discrimination of vibratory patterns. Journal of the Acoustical Society of America, 37, 797-801.

Gellatly, A. R. H., \& Cole, G. G. (2000). Accuracy of target detection in new-object and old-object displays. Journal of Experimental Psychology: Human Perception \& Performance, 26, 889-899.

Gilson, E. Q., \& BAdDELEY, A. D. (1969). Tactile short-term memory. Quarterly Journal of Experimental Psychology, 21, 180-184.

Graziano, M. S. A., Alisharan, S. E., Hu, X., \& Gross, C. G. (2002). The clothing effect: Tactile neurons in the precentral gyrus do not respond to the touch of the familiar primate chair. Proceedings of the National Academy of Sciences, 99, 11930-11933.

Hillstrom, A. P., Shapiro, K. L., \& Spence, C. (2002). Attentional limitations in processing sequentially presented vibrotactile targets. Perception \& Psychophysics, 64, 1068-1081.

Ho, C., Reed, N., \& SPEnce, C. (2006). Assessing the effectiveness of "intuitive" vibrotactile warning signals in preventing front-to-rear-end collisions in a driving simulator. Accident Analysis \& Prevention, 38, 988-996.

Ho, C., TAN, H. Z., \& Spence, C. (2005). Using spatial vibrotactile cues to direct a driver's visual attention. Transportation Research Part F, 8, 397-412.

Hochberg, J. (1968). In the mind's eye. In R. N. Haber (Ed.), Contemporary theory and research in visual perception (pp. 309-331). New York: Holt, Rinehart \& Winston.

Hollingworth, A., Williams, C. C., \& Henderson, J. M. (2001). To see and remember: Visually specific information is retained in memory from previously attended objects in natural scenes. Psychonomic Bulletin \& Review, 8, 761-768.

Holmes, N. P., \& Spence, C. (2006). Beyond the body schema: Visual, prosthetic, and technological contributions to bodily perception and awareness. In K. Gunther et al. (Eds.), Human body perception from the inside out (pp. 15-64). Oxford: Oxford University Press.

Jevons, W. S. (1871). The power of numerical discrimination. Nature, 3, 281-282.

JONIDES, J. (1981). Voluntary versus automatic control over the mind's eye's movement. In J. [B.] Long \& A. [D.] Baddeley (Eds.), Attention and performance IX (pp. 187-203). Hillsdale, NJ: Erlbaum.

Jonides, J., \& YANTIS, S. (1988). Uniqueness of abrupt visual onset in capturing attention. Perception \& Psychophysics, 43, 346-354.

Karnath, H. O., Ferber, S., \& Himmelbach, M. (2001). Spatial awareness is a function of the temporal not the posterior parietal lobe. Nature, 411, 950-953.

KIM, C.-Y., \& BlaKe, R. (2005). Psychophysical magic: Rendering the visible "invisible." Trends in Cognitive Sciences, 9, 381-388. 
LAMme, V. A. F. (2003). Why visual attention and awareness are different. Trends in Cognitive Sciences, 7, 12-18.

Lindeman, R. W., Yanagida, Y., Sibert, J. L., \& Lavine, R. (2003). Effective vibrotactile cueing in a visual search task. In G. W. M. Rauterberg, M. Menozzi, \& J. Wesson (Eds.), Proceedings of the Ninth IFIP TC13 International Conference on Human-Computer Interaction (pp. 89-98). Amsterdam: IOS Press.

Logothetis, N. K. (1998). Single units and conscious vision. Philosophical Transactions of the Royal Society of London: Series B, 353, 1801-1818.

Macmillan, N. A., \& Creelman, C. D. (2004). Detection theory: A user's guide (2nd ed.). Mahwah, NJ: Erlbaum.

Martin-Emerson, R., \& Kramer, A. F. (1997). Offset transients modulate attentional capture by sudden onsets. Perception \& Psychophysics, 59, 739-751.

Miller, G. A. (1956). The magical number seven, plus or minus two: Some limits on our capacity for processing information. Psychological Review, 63, 81-97.

Miller, J. (1989). The control of attention by abrupt visual onsets and offsets. Perception \& Psychophysics, 45, 567-571.

Mondy, S., \& Coltheart, V. (2000). Detection and identification of change in naturalistic scenes. Visual Cognition, 7, 281-296.

Nö̈, A., \& O'Regan, J. K. (2000). Perception, attention and the grand illusion. Psyche, 6(15). Retrieved April 11, 2007, from psyche .cs.monash.edu.au/v6/psyche-6-15-noe.html.

NoË, A., Pessoa, L., \& Thompson, E. (2000). Beyond the grand illusion: What change blindness really teaches us about vision. Visual Cognition, 7, 93-106.

O'Regan, J. K. (1992). Solving the "real" mysteries of visual perception: The world as an outside memory. Canadian Journal of Psychology, 46, 461-488.

O'Regan, J. K., \& Nö̈, A. (2002). A sensorimotor account of vision and visual consciousness. Behavioural \& Brain Sciences, 24, 939-974.

O’Regan, J. K., Rensink, R. A., \& Clark, J. J. (1999). Changeblindness as a result of "mudsplashes." Nature, 398, 34.

Pashler, H. (1988). Familiarity and visual change detection. Perception \& Psychophysics, 44, 369-378.

Posey, T. B., \& JAMES, M. R. (1976). Numerosity discrimination of tactile stimuli. Perceptual \& Motor Skills, 42, 671-674.

Pylyshyn, Z. W., \& StORM, R. W. (1988). Tracking multiple independent targets: Evidence for a parallel tracking mechanism. Spatial Vision, 3, 179-197.

Rensink, R. A. (2002). Change detection. Annual Review of Psychology, 53, 245-277.

Rensink, R. A., O'Regan, J. K., \& Clark, J. J. (1997). To see or not to see: The need of attention to perceive changes in scenes. Psychological Science, 8, 368-373.

Rensink, R. A., O'Regan, J. K., \& Clark, J. J. (2000). On the failure to detect changes in scenes across brief interruptions. Visual Cognition, 7, 127-145.

Simons, D. J., \& Levin, D. T. (1997). Change blindness. Trends in Cognitive Sciences, 1, 261-267.

Simons, D. J., \& Rensink, R. A. (2005). Change blindness: Past, present, and future. Trends in Cognitive Sciences, 9, 16-20.

Spence, C., \& McGlone, F. P. (2001). Reflexive spatial orienting of tactile attention. Experimental Brain Research, 141, 324-330.

Tan, H. Z., Gray, R., Young, J. J., \& Traylor, R. (2003). A haptic back display for attentional and directional cueing. Haptics-e: Electronic Journal of Haptics Research, 3. Retrieved April 11, 2007, from haptics-e.org/Vol_03/he-v3n1.pdf.

VALLAR, G. (2001). Extrapersonal visual unilateral spatial neglect and its neuroanatomy. Neurolmage, 14, S52-S58.

VanRullen, R., \& Koch, C. (2003a). Competition and selection during visual processing of natural scenes and objects. Journal of Vision, 3, 75-85.

VANRullen, R., \& Koch, C. (2003b). Is perception discrete or continuous? Trends in Cognitive Sciences, 7, 207-213.

Velichkovsky, B. M., Dornhoefer, S. M., Kopf, M., Helmert, J., \& Joos, M. (2002). Change detection and occlusion modes in roadtraffic scenarios. Transportation Research Part F, 5, 99-109.
Vitevitch, M. S. (2003). Change deafness: The inability to detect changes between two voices. Journal of Experimental Psychology: Human Perception \& Performance, 29, 333-342.

Von Haller Gilmer, B. (1960). Possibilities of cutaneous electro-pulse communication. In G. R. Hawkes (Ed.), Symposium on cutaneous sensitivity (Report No. 424). Ft. Knox, KY: U.S. Medical Research Laboratory.

Von Haller Gilmer, B. (1961). Toward cutaneous electro-pulse communication. Journal of Psychology, 52, 211-222.

WatKins, M. J., \& WatKIns, O. C. (1974). A tactile suffix effect. Memory \& Cognition, 2, 176-180.

Watson, D. G., \& Humphreys, G. W. (1995). Attention capture by contour onsets and offsets: No special role for onsets. Perception \& Psychophysics, 57, 583-597.

Williams, P. (1997). Prototypes, exemplars, and object recognition. Unpublished doctoral dissertation, Yale University.

Williams, P., \& Simons, D. J. (2000). Detecting changes in novel, complex three-dimensional objects. Visual Cognition, 7, 297-322.

Wright, M., GreEn, A., \& BAKER, S. (2000). Limitations for change detection in multiple Gabor targets. Visual Cognition, 7, 237-252.

Yantis, S., \& Hillstrom, A. P. (1994). Stimulus-driven attentional capture: Evidence from equiluminant visual objects. Journal of Experimental Psychology: Human Perception \& Performance, 20, 95-107.

YAnTIS, S., \& Jonides, J. (1984). Abrupt visual onsets and selective attention: Evidence from visual search. Journal of Experimental Psychology: Human Perception \& Performance, 10, 601-621.

\section{NOTES}

1. A preliminary study showed that participants were unable to perform the task at above $75 \%$ correct when a continuously presented $110-\mathrm{msec}$ mask was interleaved between the two to-be-discriminated vibrotactile patterns. Given this observation, a masked interval (consisting of a 10msec vibrotactile mask sandwiched between two 50-msec blanks), rather than a continuously presented $110-\mathrm{msec}$ mask, was used in the present study (cf. Gallace et al., 2006a). Note also that the 10-msec vibration was perceived subjectively by the participants to be more like a tap than a vibration. This percept presumably resulted from the fact that not enough cycles of amplitude modulation of the signal could be delivered by our device in a short enough temporal interval in order to make the stimuli appear as vibrations.

2. We performed an additional experiment in order to investigate whether participants were able to perceive changes in the overall number of vibrotactile stimuli presented in the displays. The participants $(N=$ 13) were required to identify the presence of a change between two consecutively presented displays separated by a blank interval of $110 \mathrm{msec}$ (empty-interval block), a 110-msec mask (a masked-interval block, as in Experiment 1), or presented without disruption on their skin (no-interval block). The first display was always composed of two tactors activated at a pair of randomly chosen body locations, whereas the second display was composed of either one (removal condition), two (no-change condition), or three (addition condition) tactors activated. The participants' $d^{\prime}$ and $\beta$ values were calculated using signal detection theory. These measures were submitted to a repeated measures ANOVA with the factor of block type (three levels: no interval, empty interval, and masked interval). The analysis of the sensitivity data revealed a significant main effect of block type $[F(2,26)=100.4, p<.0001]$. A Duncan post hoc test revealed significant differences among all three experimental conditions (all $p \mathrm{~s}<.05$ ), with the lowest $d^{\prime}$ value being reported in the masked interval condition and the highest value in the no-interval condition. The analysis of the response bias data revealed no significant effect of block type $[F(2,26)<1$, n.s. $]$. The results of this control experiment therefore showed that people can fail to detect the presence of a change between two sequentially presented vibrotactile patterns delivered over the body surface, even under conditions in which the changes are predictable on the basis of the number of stimuli presented in the display.

(Manuscript received September 14, 2005; revision accepted for publication August 14, 2006.) 